УАK 316.334 .3

ББК 66.3(0),4

DOI 10.22394/1682-2358-2017-6-102-107

R.A. Levocbkin, post-graduate student at the Political Science and Public Administration Department, Central Russian Institute of Management, Branch of the Russian Presidential Academy of National Economy and Public Administration

\section{THE MAIN \\ DIRECTIONS \\ OF OPTIMIZATION \\ OF THE STATE YOUTH \\ POLICY \\ IN THE REGION}

The main directions of optimization of the state youth policy in the region are investigated. The author marks out the institutional frameworks of staffing policy implementation. Special attention is paid to the staffing of youth policy. As a result of the research, a number of proposals are made regarding the implementation of the state youth policy at the regional level.

Key words and word-combinations: youth, state youth policy, optimization of state youth policy.
P.A. Мевочкин, аспирант кафедрь политологии, государственного и муниципального упраљления Среднерусского института упраљления - филиала Российской академии народного хозяйства и государственной службъ при Президенте РФ (email: eler12@mail.ru)

\section{ОСНОВНЫЕ НАПРАВАЕНИЯ ОПТИМИЗАЦИИ ГОСУААРСТВЕННОЙ МОАОАЕЖКНОЙ ПОАИТИКИ В РЕГИОНЕ}

Аннотация. Исследуются основные направления оптимизации государственной молодежной политики в регионе. Обозначены институциональные рамки реализации кадровой политики. Особое внимание уделяется кадровому обеспечению молодежной политики. Формулируется ряд предложений по реализации государственной молодежной политики на региональном уровне.

Ключевые слова и словосочетания: молодежь, государственная молодежная политика, оптимизация государственной молодежной политики.

$\mathrm{O}_{1}$ птимизация государственной поАитики в молодежной сфере является непрерывным проџессом ее модернизаџии, с выбором наиболее эффективных и целесообразных направлений и учетом вмияния общественных изменений и иных факторов. Выбор базовых направлений оптимизаџии государственной молодежной политики зависит не только от положкения дел в молодежной среАе, но и от эффективности осуществляемой в регионе соответствующей политики. При этом необходимо про- 
ведение научных исследований по ряду причин. Во-первых, с целью выбора наилучшего варианта стратегий государственной молодежной политики в соответствии со спещификой региона необходим анализ теоретико-метоАологической базы; во-вторых - обоснование оптимальных векторов модернизации молодежной политики и анализ ее ресурсного обеспечения; в-третьих - определение базовых направлений модернизации молодежной политики в регионе.

С.Н. Чирун отмечает, что оптимизация механизмов и способов реализации государственной молодежной политики в регионе является проџессом приведения ее в положение, наиболее благоприятным образом соответствуюшее интересам молодых граждан и населения региона в целом [1, с. 137]. В этом случае оптимизаџия будет направлена на корректировку и модернизаџию каких-либо положений или молодежной политики в целом, хода и условий ее исполнения в регионе.

Оптимизации государственной молодежной политики содействует реализация принџипов, цемей и современных требований, преАставленных в Основах государственной молодежной политики Российской Федераџии на период до 2025 г., утвержденных распоряжением Правительства РФ от 29 ноября 2014 г. № 2403-р и формируют, на наш взгляА, институциональные рамки ее реализации на региональном уровне [2] .

Указанные требования выражаются в следующих положениях:

1. Инициатива молодых граждан - это потенциал развития Российской Федерации (поддержка и содействие в становлении гражданских иниџиатив молодых граждан, поошрение молодежного самоуправления, стимулирование работы детских и молодежных общественных объединений).

2. Интересы молодых граждан должны быть направлены на благо общества (переподготовка работы молодежных центров в соответствии с интересами молодежи и современными потребностями, а также формирование новейшей инфраструктуры молодежной политики).

3. Инвестиџионность и инновационность (установление принџипа Алительного инвестирования на расходы в обцасти государственной молодежной политики, а также прогноза вероятного объема прибыли).

4. Сотрудничество и интеграция (обозначение приоритетности государственной политики в области молодежи как межотраслевой сферы, совокупное применение материальной основы учреждений различных ведомств; подготовка молодежных разделов в инвестиционных и целевых программах различных уровней).

5. Информативность (интерактивное взаимодействие молодежи и государства в информаџионных мировых сетях; формирование всероссийского молодежного информационного портала).

6. Аиверсификаџия государственной молодежной политики (применение многогранного подхода к молодым гражданам по возрастным и соџиальным группам, создание новых технологий и среАств в работе с молодежью).

7. Аиалог с молодыми Аюдьми («круглые столы», встречи, проведение фес- 
тивалей иниџиатив молодежи, формирование общественных объединений творческой, сельской, рабочей в симовых структурах молодых гражАан).

8. Общедоступность соџиальных услуг (снабжение учреждений в области молодежной политики современным оборудованием, увеличение роли экономических секторов в привлечении ресурсов).

В каждом конкретном регионе государственная политика в области молодежи имеет свою специфику, конкретизированную особенностями региональной стратегии и уровнем соџиального и экономического развития. К примеру, в Орцовской области эта стратегия отражается в подготовке и исполнении программы по увекичению уровня жизни населения [3] - одном из направмений деятельности органов вмасти и управления региона. В ней делается акцент на принципиально важный момент: пришло время изменить кризисную психомогию выживания, безысходности на позитивную, рассчитанную на поддержку обшества и собственные силы. Нужна стратегия управления, ориентированная на человека, на соџиальный рынок.

Государственная молодежная политика в контексте стратегии качества Аолжна быть направлена на повышение уровня жизни молодых граждан. Ее базовые векторы следует реализовывать с учетом преАставления программы приоритетов, что требует оптимизации механизма региональной молодежной политики.

Осуществление программно-целевого подхода в этой Аеятельности преАполагает установление промежуточных и перспективных целей развития учреждений; формулировку базовых направмений, цемедостижения; выработку критериев, конкретных задач, средств, путей реализаџии стратегических направмений развития; создание программ, подпрограмм Амя решения важных задач в поле имеющегося потенциала ресурсного обеспечения.

Реализация программно-целевого подхода сопровождается переменой стиля управления. Программно-целевое управление предполагает анализ перспективы, что отвечает креативно-активному подходу к управлению, осуществляемому в определенных проектах. Соџиальные программы явцяются их текстовыми формами. П.Н. Беспаленко обосновывает, что они могут быть оригинальными ступеньками к триумфу конечных цемей общественного проекта, базовыми инструментами его исполнения [4, с. 68]. Именно в программах реализуется соџиальный проект в виде текстового документа. Из этого следует, что общая молодежная политика в регионе, ориентированная на увеличение уровня жизни молодых граждан, должна преАставлять собой текстовую форму специфического общественного проекта, то есть это социальное нововведение сформированное его инициаторами. В.П. Щербакова отмечает, что модернизаџией соџиального проекта могут быть решены задачи повышения качества самореализации и соџиализации молодых граждан, а также задачи по целесообразному использованию молодежного капитала страны [5, с. 283].

Претворение в жизнь молодежной программы предусматривает использование новейших соџиальных технологий и, как правимо, они еще не ап- 
робированы в силу инновационности их технологии. Все это предполагает модернизаџию фимософии соџиального проектирования в области молодежной политики. Базой для новой конџептуальной установки явАяется субъективно-субъективная парадигма общественного взаимодействия, где ни один из участников данного проџесса не использует другого Аля достижения своих мичных целей, отношения базируются на взаимном заинтересованном партнерстве [6] .

Осуществление государственной молодежной политики в регионе обеспечивается конџептуальностью проектирования, что означает следующее:

- существование системы принципов при формировании молодежных программ;

- наличие единого замысла проекта в достижении баланса между его инициатором и молодежью;

- социально-технологическое обоснование при разработке мероприятий.

В ходе формирования и реализаџии молодежной политики важно установить ключевое звено, при помощи которого можно эффективно решить целый спектр проблем. Как показывает опыт, в роли такого кмючевого звена выступает кадровое обеспечение в сфере региональной молодежной политики. А. $\Lambda$. Елисеев считает, что невозможно совершенствовать государственную молодежную политику без квалифицированных каАров. Важно предусмотреть комплекс мер поддержки и закрепления специалистов в этой области в разных условиях $[7$, с. 80].

Государственная молодежная политика обязана сопровождаться системой мер, создающих одобрительнее общественное мнение. Эта работа может осуществцяться по направлениям: поиск кадров исследоватемей, вырабатывающих проблему оптимизации молодежной политики; реализаџия определенных исследований по данной проблеме; публикация аналитических трудов; подготовка статистических данных по проблемам молодежи; публицистические выступления в СМИ.

Аеятельная молодежная политика может быть реализована только при решенных ресурсных проблемах с помощью нескольких источников на базе принципов многоуровневого финансирования: во-первых, за счет среАств, выделенных из федерального бюАжета; во-вторых, из бюджета области; втретьих, из фонда соџиального развития. Регулирование области молодежной политики связано с нормативно-правовым обеспечением с помощью результативного использования существующих законов и Аругих нормативно-правовых актов, а также с применением новых законов в реально существующей ситуации.

Государственная поддержкка в области молодежки на региональном уровне нуждается в модернизации и переходе к инновационной модеми управления на базе прогнозирования, глубокого анализа и демократических принщипов. Это должно решаться в первую очередь путем взаимодействия муниципальных и государственных структур с молодежными общественными организациями. Механизм молодежной политики вырабатывается в проџессе форми- 
рования системы обеспечения, обладающей организационно-управленческим элементом, нормативно-правовым обеспечением, научно-аналитическим и ресурсным обеспечением. Отметим, что процесс создания молодежных региональных структур еще не завершен. Это связано с несовершенством системы ресурсного обеспечения, законодательной базы и иных проблем, требующих решение.

Таким образом, главными проблемами политики в молодежной сфере явмяются отсутствие полной законодательной базы для решения молодежных проблем; немногочисленность специалистов в структурах по делам молодежи на различных уровнях; недостаточность финансового и технического оснащения этой работы; отсутствие координации и неурегулированность взаимоотношений в деятельности разАичных ведомств, что приводит к несвоевременному принятию эффективных решений; недооценка со стороны руководящих структур молодежных проблем; недостаточное научное и методическое обеспечение социальной работы с молодежью и государственной молодежной по-

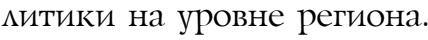

Вопреки тому, что ежегодно высшие учебные заведения выпускают немало специалистов в области работы с молодежью, у выпускников низкая мотивация работать по специальности, а также существует проблема с их трудоустройством. Аля этого первоочередной задачей явмяется разработка механизма по подготовке специалистов молодежной сферы с учетом требований в данной отрасли, а также закрепление сформированной профессиональной модели специалиста в сфере молодежной политики.

Возникает потребность в возобновлении деятельности институтов гражАанского обшества, на содействие которых может рассчитывать молодежк Российской Федерации: молодежкных совещательных и представительных структур, политических партий, молодежных среАств массовой информаџии, ассоџиаций предпринимателей, независимых профсоюзов и иных. Такие институты смогут направить энергию и потенџиал молодых мюдей на благо общества. Органы молодежжного представительства, с одной стороны, расширяют сферу своего воздействия в органах муниџипального и государственного управления, а с Аругой - реализуют интересы молодых граждан в мегальных институтах вАасти.

Молодые граждане могут принимать участие в принятии решений органами власти, напрямую касающихся их жизни, а также в создании системы содействия иниџиативам молодежных общественных организаций. Наличие и работа молодежных общественных организаций является показателем зрелости гражданского общества. В связи с этим возникает потребность в модернизации системы мер, направленных на формирование условий и возможностей дмя эффективной самореализаџии молодежки [8, с. 97]. Подготовка и осуществмение молодежной политики, опирающейся как на интересы молодых граждан, так и на стратегические цели развития субъектов РФ, превращается в необходимость, в важный фактор повышения качества. 


\section{Библиографический список}

1. Чирун С.Н. Молодежная политика в регионе: пути оптимизации, методология // Вестник Кузбасского государственного технического университета. 2004. С. 133-139.

2. Основы государственной молодежной политики Российской Федерации на период до 2025 г.: Распоряжение Правительства Российской Федерации от 29 нояб. 2014 г. № 2403-p // СЗ РФ. 2014. № 50. Ст. 7185.

3. О государственной молодежной политике в Орловской области: Закон Орловской области от 3 дек. 2010 г. № 1154-ОЗ (в ред. от 25 дек. 2013 г.) // Орловская правда. 2010. № 181.

4. Беспаленко П.Н. Проектирование государственной молодежной политики в практике муниципального управления: автореф. дис. ... канд. социол. наук. Белгород, 2001.

5. Щербакова В.П. Государственная молодежная политика в современном российском обществе как фактор оптимизации социальной адаптации молодежи // Известия Тульского государственного университета. Сер.: Гуманитарные науки. 2012. С. 276-287.

6. Батурин B.C. Новая парадигма социальной деятельности как определяющее условие построения правового государства // XXI век: будущее России в философском измерении: материалы Второго российского философского конгресса. Т. 2: Социальная философия и философия политики. Екатеринбург, 2013. С. 102-103.

7. Елисеев А.Л. Кадровое обеспечение реализации государственной молодежной политики на федеральном, региональном и муниципальных уровнях // Вестник государственного и муниципального управления. 2014. № 3 (14). С. 79-82.

8. Меркулов П.А., Елисеев А.Л. Региональная государственная молодежная политика: проблемы и перспективы // Государственное управление. Электронный вестник. 2015. № 52. C. $87-100$. 